\title{
CONSERVAÇÃO, COMUNIDADES LOCAIS E TERRITÓRIO: NATUREZA PARA QUEM?
}

Carlos Alberto Marçal Gonzaga ${ }^{1}$

Patrícia Denkewicz ${ }^{2}$

Rui Pedro Julião ${ }^{3}$

Resumo: Este artigo apresenta conflitos socioambientais de uma ilha turística no sul do Brasil. A llha do Mel, situada à entrada da Baía de Paranaguá, constituiu-se em um commons de recursos naturais para pescadores de populações tradicionais caiçaras. A criação de duas Unidades de Conservação impôs um plano de uso do solo que remanejou populações, restringiu-lhes acesso a recursos comunitários e originou conflitos relacionados à regulação territorial. $O$ estudo baseou-se em observação participante e análise documental. Os resultados evidenciam que a normatização estatal afrontou direitos humanos e constitucionais das comunidades nativas tradicionais. Argumentamos que o modelo de proteção ambiental utilizado é paradoxal aos objetivos de desenvolvimento sustentável.

Palavras-chave: Ordenamento Territorial. Conservação Ambiental. Conflito Socioambiental.

\section{CONSERVATION, LOCAL COMMUNITIES AND TERRITORY: NATURE FOR WHO?}

Abstract: This article presents socio-environmental conflicts on a subtropical tourist island. Ilha do Mel (Island of Honey), located on the coast of the State of Paraná, in the south of Brazil, constituted a common pool of resources for fishermen of native Caa-Icaras populations, during almost the entire 20th Century. The establishment of two integral Conservation Units imposed population relocations and land use restrictions that led to strife for socio-environmental justice. Conflicts are related to territorial regulation and infrastructure management. The study was based on bibliographic references and documentary analysis, considering the legal framework and the concepts of the analytical fields. The results show that the territorial regulation violates human and constitutional rights of local native communities. We argue that the State environmental protection model is paradoxical with sustainable development objectives.

Keywords: Territorial Planning. Environmental Conservation. Socio-environmental Conflict.

\section{CONSERVACIÓN, COMUNIDADES LOCALES Y TERRITORIO: ¿NATURALEZA PARA QUIÉN?}

Resumen: Este artículo presenta conflictos socioambientales en una isla turística subtropical. La Isla de Miel, ubicada en la costa del Estado de Paraná, en el sur de

\footnotetext{
${ }^{1}$ Universidade Estadual do Centro-Oeste, Administração, Irati, Brasil, gonzaga@unicentro.br, https://orcid.org/0000-0001-8446-6112

2 Universidade Estadual do Paraná, Turismo, Campo Mourão, Brasil, patriciadenkwicz@gmail.com, https://orcid.org/0000-0002-5045-3222

${ }_{3}^{3}$ Universidade Nova de Lisboa, Geografia e Planeamento Regional, Lisboa, Portugal, rpj@fcsh.unl.pt, https://orcid.org/0000-0002-5625-9965
} 
Brasil, constituyó un commons de recursos naturales para los pescadores de las poblaciones tradicionales de Caa-lcaras, durante casi todo el siglo XX. El establecimiento de dos Unidades de Conservación integrales impuso reubicaciones de población y restricciones de uso de la tierra que llevaron a la lucha por la justicia socioambientales. Los conflictos están relacionados con la regulación territorial y la gestión de la infraestructura. El estudio se basó en referencias bibliográficas y análisis documental, considerando el marco legal y los conceptos de los campos analíticos. Los resultados muestran que la regulación territorial instituida viola los derechos humanos y constitucionales de la comunidad nativa local. Argumentamos que el modelo de protección ambiental del Estado es paradójico con los objetivos de desarrollo sostenible.

Palabras clave: Planificación del Uso del Suelo. Conservación del Medio Ambiente. Conflicto Socioambiental.

\section{Introdução}

A transformação dos bens naturais em mercadoria promove uma confrontação discursiva manifesta em conflitos socioambientais estruturais, que aparentam fundar-se em simples questões particulares específicas. No entanto, expressam diferentes concepções de realidade e de significado para a natureza, resultando nas disputas sobre os modos de apropriação dos bens naturais (ACSELRAD, 2004). Assim, os casos aparentemente isolados de conflitos socioambientais territoriais em várias partes do mundo são expressão local do processo global de apropriação da natureza para o consumismo hedonista e a concentração do capital.

Desde as últimas décadas do segundo milênio, cresceu a percepção de que há uma crise ambiental no planeta Terra. A exploração inadequada e os processos de alta entropia utilizados na transformação dos recursos naturais agravaram os problemas ambientais, percebidos e vivenciados de forma distinta nos níveis global e local (HOSOKAWA; HOSOKAWA, 2001). As evidências dessa crise estariam visíveis no ritmo acelerado da produção industrial, nos hábitos de consumo humano e na quantidade e qualidade dos descartes de resíduos. Os excessos teriam exacerbado a depleção dos ecossistemas ao ponto de causarem irreversível ruptura (ALTVATER, 1993. PIERRI, 2001. COSTA, 2016).

A crise ecológica se caracteriza como a manifestação concreta da ruptura entre a humanidade e a natureza (OST, 1995). Traduz-se numa crise do paradigma hegemônico, porque distancia os seres humanos dos processos naturais e conduz a uma imprevisibilidade aleatória de incertezas. Resultam as dificuldades para controlar as dimensões espaciais e temporais dos danos ambientais causados pelas 
ações antrópicas, que extrapolam as fronteiras das localidades em que ocorrem e podem perdurar por séculos (MARQUES, 2013). Estaria comprometida a sustentabilidade para as futuras gerações.

Somam-se as evidências de que os problemas ambientais do planeta Terra estão associados ao resultado das atividades humanas (BIERMANN, 2014. SONG, et al, 2018. BÜSCHER; FLETCHER, 2019, 2020). Considerando como irreversíveis as mudanças resultantes dessa crise, Crutzen (2002) propõe a identificação de uma nova era geológica, designada Antropoceno. Caracteriza-se pela influência das atividades humanas sobre todos os processos não humanos no planeta, iniciada ao final do Século XVIII, após a invenção da máquina a vapor, quando se aceleram os níveis de emissão antrópica de CO2 na atmosfera (CRUTZEN, 2002; 2016. STEFFEN. et al, 2011). Embora ainda haja divergências sobre a adequação do uso do termo (MALM; HORNBORG, 2014), a designação tornou-se amplamente citada e aceita em várias ciências (STEFFEN. et al, 2011. BÜSCHER; FLETCHER, 2020). Com isso ganha relevo a superação da ideia de que exista ainda alguma natureza intocada e autônoma.

O impacto desse predomínio antrópico se reflete no comportamento e na ética do relacionamento dos seres humanos com as outras espécies e com a natureza em geral. As decisões sobre a expansão das fronteiras de exploração dos recursos naturais, ou sua conservação, cobrem um amplo espectro de posicionamentos técnicos e ideológicos. Enquanto, por um lado, prevalece o conservacionismo tradicional que exclui os seres humanos das áreas protegidas supostamente 'intocadas', por outro lado ganham proeminência as soluções neoliberais de guiar a sustentabilidade pelos mecanismos de mercado, que instigam proposições de ruptura que se autoproclamam pós-capitalismo (BÜSCHER; FLETCHER, 2019; 2020).

Cresce a necessidade de terras agrícolas, pastagens, áreas urbanas e insumos industrializados. Do mesmo modo, o crescimento da aquicultura e a expansão da extração de recursos nas áreas costeiras e marinhas, rumo às águas mais profundas e distante da costa, são indicativos da limitação dos recursos terrestre. (FOLEY et al., 2005. DOUVERE, 2008). Como consequência, ocorre a expansão das fronteiras de exploração intensiva nos países cuja potencialidade se deve à abundância de recursos naturais preservados. O capital mundial articula diferentes partes desses territórios ao mercado globalizado, em que o meio ambiente se submete à economia (ALTVATER, 1993. CHIARELLA, 2011). As 
economias desenvolvidas expandem sua hegemonia de mercado em transações econômicas baseadas na criação de novas commodities imateriais, como créditos de carbono e patentes, aprofundando as desigualdades sociais, de gênero e étnicas (NEILSON; CASTRO, 2016).

A expansão espacial das fronteiras de extração de um recurso mascara o seu esgotamento no nível regional. Essa é uma característica comum resultante da exploração contínua excessiva (BERKES et al., 2006). A apropriação de parcela crescente dos recursos do planeta reduz a sustentabilidade dos ecossistemas para produção de alimentos, fornecimento de água potável, purificação do ar, estabilização das mudanças climáticas, absorção de resíduos e resiliência diante das doenças infecciosas (FOLEY et al., 2005. POTDAR et al, 2016. LETCHER; VALLERO, 2019).

O modelo predominante de desenvolvimento orientado pela lógica de mercado alavanca uma série de impactos negativos sobre os ecossistemas. Tais impactos engendram injustiças ambientais relacionadas à desigualdade na distribuição social do ônus resultante. A percepção dessas injustiças, associada às ameaças reais de mudanças compulsórias das bases materiais de subsistência, deflagra vários conflitos socioambientais relacionados à ocupação e uso do solo.

Diante da exploração e utilização insustentável dos recursos finitos do planeta, originando a eclosão crônica de problemas sociais, conceitos como sustentabilidade e desenvolvimento sustentável passaram a ter uso generalizado e inespecífico. Servindo a várias finalidades e justificativas, a expressão desenvolvimento sustentável tem sido utilizada como um guarda-chuva para discursos que se pretendem apolíticos e ambientalmente corretos, embora impulsionem a homogeneização da cultura e da educação ambiental globalizada (NEILSON; CASTRO, 2016). Enquanto isso, as desigualdades socioeconômicas são crescentes. A pobreza e a insegurança alimentar e nutricional manifestam-se como um inconveniente paradoxal num sistema econômico que, no início do Século 21 , registrou crescimento historicamente incomparável com o de outras épocas.

As formas de interação e apropriação da natureza se materializam de diferentes maneiras e significações sociais, determinando territorialidades específicas em cada localidade. No entanto, dadas às assimetrias de poder nas sociedades contemporâneas, consolidou-se a hegemonia de uma visão de mundo assente num modelo de natureza intocada e desvinculada da existência humana (MARTINEZ-ALIER, 2004. LIRA; WITKOSKI, 2016. BÜSCHER; FLETCHER, 2019, 
2020). Essa visão orienta a instituição de políticas públicas que se refletem na forma de ordenação territorial dos lugares, particularmente em sua dinâmica econômica de reprodução social (LIMA; BRASIL; LOCATEL, 2018). Assim, legitimam-se privilégios ambientais dos habitantes de algumas regiões, resultando num mosaico espacial que configura desigualdades, injustiças e conflitos socioambientais (MARTINEZALIER, 2004).

A origem dos conflitos socioambientais está na percepção da desigualdade de direitos, entre os grupos sociais, quanto ao compartilhamento dos benefícios e dos riscos relativos à extração dos recursos de uso em comum num território. $O$ discernimento, por um grupo social, de que a continuidade das suas formas de apropriação, uso e significação do território estão ameaçadas, conduz ao conflito. A manifestação explícita dos conflitos expõe desigualdades, privilégios e preconceitos, que elucidam a divisão social do ônus e dos sacrifícios decorrentes da poluição e utilização desmesurada dos bens naturais (MARTINEZ-ALIER, 2004. ACSELRAD, 2004; 2010. MARTINEZ-ALIER; WALTER, 2016). A consciência de que se alcançou o Período Antropoceno tornou mais difícil conciliar todos os interesses divergentes em torno de um único ideal de sustentabilidade (BÜSCHER; FLETCHER, 2019).

Este artigo apresenta o estudo dos conflitos socioambientais resultantes da implantação de duas Unidades de Conservação na llha do Mel, seguida da imposição de um plano de manejo e uso do solo disruptivo para a organização socioeconômica local. A agência ambiental do governo justificou as restrições territoriais como um trade off preventivo em face do risco de substituição dos ecossistemas locais por condomínios de férias privados para populações urbanas capitalizadas, o que causaria degradação da biodiversidade e gentrificação.

Além desta introdução, o artigo contém uma revisão bibliográfica com base nas tendências de discussão do tema na literatura recente. Na terceira seção consta a explanação dos procedimentos metodológicos e a caracterização do caso analisado. Na quarta seção apresenta-se a análise documental que baseia a discussão. Na quinta seção estão as considerações finais.

Os resultados identificam evidências de que foram executadas ações estatais ao arrepio das disposições constitucionais brasileiras, em confronto com os princípios dos direitos humanos e outras normas e convenções. Com base nas observações a campo e na literatura, defende-se a gestão ambiental comunitária e participativa, por meio do diálogo entre os múltiplos stakeholders, em que nenhuma das partes se considera portadora de conhecimentos superiores em relação aos 
demais e prevaleçam comprometimento pelo manejo sustentável do território. A pesquisa oferece base para produzir novos conhecimentos sobre a interação (ou falta dela) entre os atores sociais envolvidos no conflito socioambiental estudado.

\section{Revisão Bibliográfica}

As confrontações socioambientais estão associadas a apropriações não negociadas de um território e seus elementos constitutivos. Principalmente quando os recursos em disputa constituem a base material e simbólica para um conjunto de indivíduos, inclusive para sua reprodução social (ZHOURI; LASCHEFSKI, 2010). Os conflitos socioambientais podem resultar de mudanças econômicas que impliquem na 'socialização' dos custos sociais resultantes da ocupação e uso do solo, beneficiando alguns grupos em detrimento dos interesses de outros, presentes ou futuros. Geralmente são as populações empobrecidas e as minorias sociais vulnerabilizadas e marginalizadas que suportam a carga maior dos custos ambientais, legitimando a demanda por justiça ambiental (MARTINEZ-ALIER, 2004. ACSELRAD; MELLO; BEZERRA, 2009, ANGUELOVSKI, 2015).

O poder de decisão sobre a redistribuição dos custos socioambientais deriva da estrutura de relações socioeconômicas, onde se definem os lugares e os limites de ação de cada grupo social. Todas as atividades humanas causam impacto sobre o meio ambiente, embora tais impactos sejam socialmente diferenciados em escala. As comunidades pobres que dependem dos recursos presentes em seu território de vida causam impacto localmente observável. Por outro lado, os grupos sociais que concentram o capital e o poder causam impacto globalmente difuso, intermediado pelo comércio internacional de commodities, porque mantém um padrão de consumo dependente dos recursos de todo o planeta (GONZAGA, 2018).

A capacidade de intervenção e influência dos grupos sociais em confronto depende da determinação de qual será a linguagem predominante para a interpretação da realidade em avaliação. Os grupos e indivíduos envolvidos em conflitos usam linguagens específicas de seu meio cultural para definir os temas importantes numa discussão. Quem define a linguagem predominante das negociações tem mais poder para influenciar os resultados e a distribuição dos custos ambientais (MARTINEZ-ALIER, 2004; 2016).

A institucionalização de termos como desenvolvimento sustentável, crescimento sustentado, vantagem competitiva, etc., oculta o subterfúgio de evitar o 
questionamento e a responsabilização do padrão de consumo urbano-industrial, que conduz à excessiva apropriação territorial e extração de elementos da natureza. A suposta política igualitária de equalização, entre todos, da responsabilidade pela degradação ambiental conduz a uma divisão social injusta dos custos ambientais e reproduz as desigualdades socioeconômicas existentes (MARTINEZ-ALIER, 2004; MONTEIRO; PEREIRA; GAUDIO, 2012).

As Unidades de Conservação (UCs) ambiental, a partir da segunda metade do Século XX, tornaram-se uma estratégia predominante de políticas ambientais, no âmbito de governos nacionais, em resposta às evidências de extinção de várias espécies em nível global (MEA 2005. HUTTON; ADAMS; MUROMBEDZI, 2005. ADAMS; HUTTON, 2007). A decisão política de criar UCs acomoda vários benefícios socioambientais, que deveriam estar ao alcance das comunidades que os preservaram (SANTOS; SCHIAVETTI, 2014). No entanto, a criação de UCs tende a engendrar múltiplos conflitos ambientais, majoritariamente por causa da concepção de que os seres humanos representam entrave aos objetivos conservacionistas (ADAMS; HUTTON, 2007. CASTRO-JR; COUTINHO; FREITAS, 2009. SPINOLA, 2013. BÜSCHER; FLETCHER, 2020).

No Século XXI, passou a haver grande pressão social e política para a criação de unidades de conservação em áreas costeiras e marinhas (SANTOS; SCHIAVETTI, 2014. MAESTRO et al., 2019). Não só devido à acelerada deterioração dos ecossistemas marinhos, mas pela mobilização dos organismos internacionais em realizar o ordenamento espacial dos oceanos, com referencial nos conceitos de 'economia azul' e 'blue growth' (BARBESGAARD, 2018). A ocupação antrópica e uso do solo nos ecossistemas costeiros implicam em grande pressão sobre a dinâmica da paisagem, cuja intensidade depende do tipo de atividade predominante (DINIZ et al, 2019). A complexidade e fragilidade dos ecossistemas litorâneos diante dos mínimos desequilíbrios ecológicos, requer diálogo e comprometimento entre atores que se confrontam pelo seu ordenamento territorial.

As tomadas de decisões participativas são previstas nos instrumentos jurídicos e constituem-se importante procedimento para incentivar a produção de novos conhecimentos, configurações organizacionais e práticas gerenciais sustentáveis (FRANÇA, 2019). No entanto, muitas vezes a participação ocorre mais como uma formalidade burocrática, conduzida como instrumento de legitimação para decisões que priorizam interesses desvinculados da perspectiva de comunidades 
locais sem capital político, porque seus conhecimentos são subvalorizados e ignorados (NEILSON; SÃO MARCOS, 2016; MENON; GONZAGA, 2017).

$A$ análise das interações entre comunidade tradicionais e os meios físico e biótico das Unidades de Conservação implica numa discussão em torno de questões éticas, sociológicas e jurídicas, visto que está em causa a contestação não só da permanência, mas da própria existência da comunidade (SPINOLA, 2006).

\section{Materiais e Métodos}

A pesquisa foi realizada com abordagem qualitativa e descritiva. Os dados foram obtidos por meio de análise documental e observação participante. A escolha do método qualitativo teve a finalidade de buscar o sentido implícito nos fatos observados, para vislumbrar possíveis soluções aos problemas identificados. Não houve intenção de quantificar valores nem realizar trocas simbólicas. Os resultados foram analisados com base em pesquisa bibliográfica de literatura relevante na área de estudo.

A revisão bibliográfica foi elaborada com assistência da metodologia de análise bibliométrica Methodi Ordinatio (PAGANI; KOVALESKI; RESENDE, 2015). Esta ferramenta auxilia na busca e identificação da literatura científica relevante para discutir um tema de estudo, baseando-se na quantidade de citações, idade da publicação e fator de impacto do periódico. As bases de dados consultadas foram: Web of Science, Scopus, Science Direct, e Scielo. Os termos de busca, com utilização de operadores boleanos, foram: (("territor* plan*" OR "land use plan*") AND "environment" conflict"). Além disso, foram utilizadas referências da literatura sobre as políticas e práticas de conservação ambiental no Brasil.

\section{Caracterização da Área de Estudo}

O objeto deste estudo foi o conflito socioambiental entre a comunidade tradicional da Ponta Oeste e a Estação Ecológica da Ilha do Mel (PR), uma Unidade de Conservação de proteção integral (Figura 1). Para sua implantação a comunidade foi destituída de seu território e teve suas atividades produtivas limitadas, circunstâncias que originaram o conflito. 


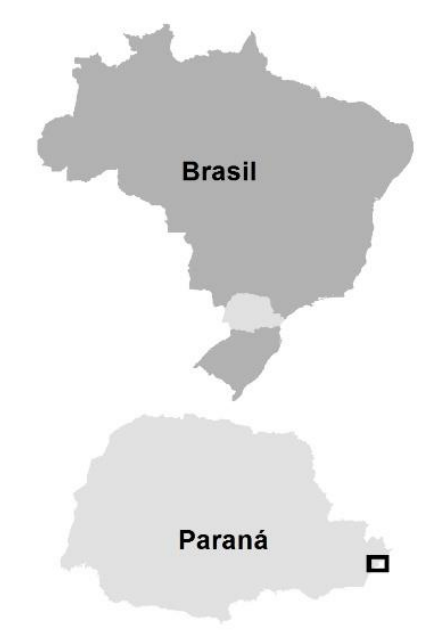

\section{ILHA DO MEL}

Sistema de Coordenadas SIRG $\Lambda$ S 2000 UTM Zone $22 S$ Projeção: Transverse Mercator

Comunidades

Figura 1 - Mapa da llha do Mel

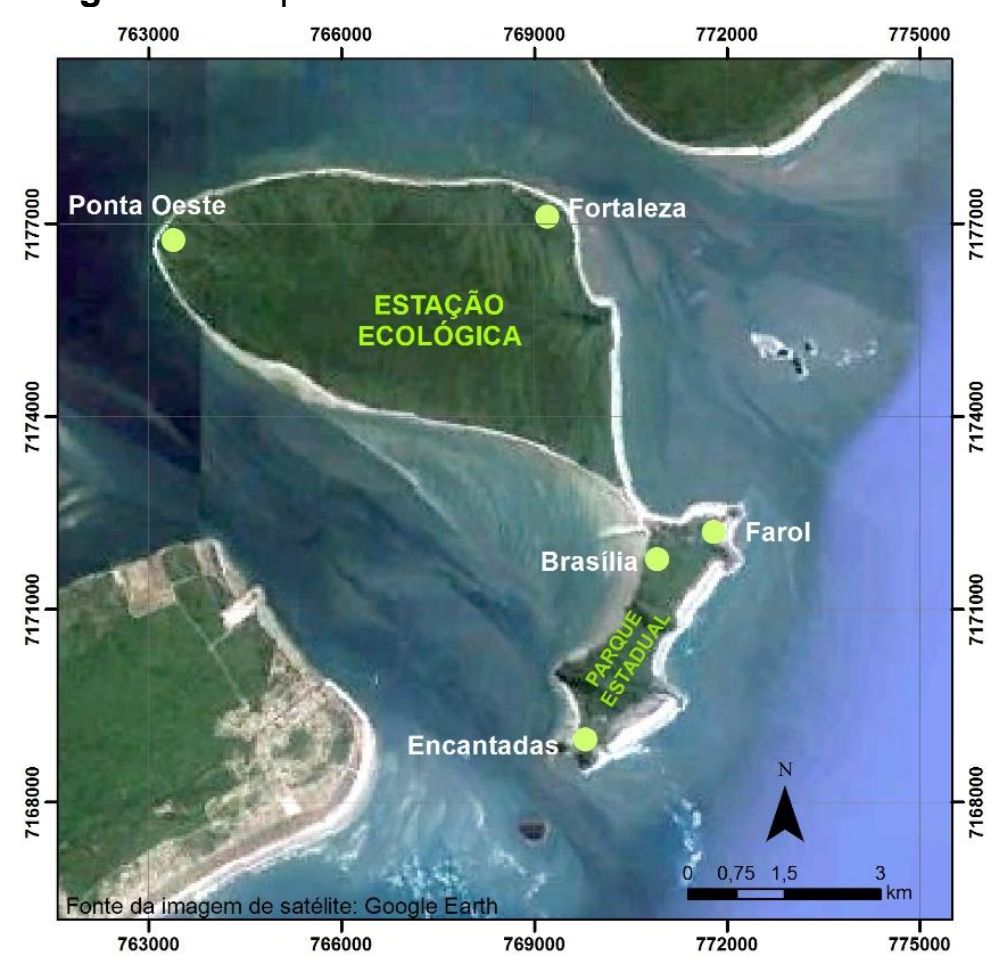

Fonte: Denkewicz, 2020.

A Ilha do Mel (Figura 1) está posicionada nas coordenadas geográficas: norte

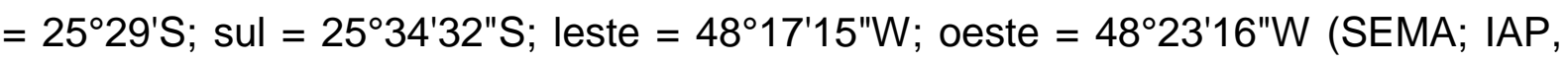
1996). Situa-se na entrada da Baía de Paranaguá, ao lado do canal que dá acesso a um dos maiores portos marítimos da América do Latina, no litoral sul do Brasil. Sua área total é de 2.762 hectares, dos quais 2.578 hectares foram transformados em Unidades de Conservação de proteção integral (Estação Ecológica e Parque Estadual). Após a instituição das UCs, o ordenamento territorial restringiu a ocupação e uso de $93 \%$ da área da llha.

A criação da Estação Ecológica da llha do Mel, em 1982, com 2,2 mil hectares de área, teve como finalidade a preservação dos ecossistemas de manguezais, restingas, brejos litorâneos e caxetais, no lado oeste. Sua criação deveu-se, primariamente, ao atendimento de uma das condições impostas pela Marinha do Brasil, no termo de aforamento, para transferência de sua gestão ao Governo do Paraná do Estado do Paraná (SEMA; IAP, 1996). O Parque Estadual da Ilha do Mel, instituído em 2002, com 338 hectares de área, tem a finalidade de proteger os mananciais de abastecimento local, os sítios históricos e arqueológicos e um bosque remanescente de Floresta Atlântica, na região sul da Ilha (PARANÁ, 2002). Em nenhum dos casos houve consulta prévia à população local. 
Há relatos históricos sobre a presença de população indígena na llha do Mel, da etnia Guarani/Mbya (LADEIRA, 1990), remontam ao período inicial da ocupação europeia no litoral da América Latina (SANTOS, 1850, apud SEMA; IAP, 1996), constando em registros de viagens de náufragos e de pesquisadores, como Hans Staden e Saint-Hilaire (FIGUEIREDO, 1954, apud WESTPHAL, 2014). Pelo recenseamento oficial de 2010, a população da llha do Mel era de 1.094 habitantes (IBGE, 2010). Porém, numa pesquisa de campo, realizada em 2014, estimou-se que a população residente se aproximava de três mil pessoas (GONZAGA; DENKEWICZ; PRADO, 2014). A discrepância de resultados se explica pelo grande fluxo turístico, baixo controle de entrada e saída de visitantes, ocorrência de residentes irregulares e residentes temporários.

A ocupação desordenada é observada no diagnóstico do Plano de Manejo do Parque Estadual da llha do Mel (IAP, 2012). A anomalia é constatada pela comparação entre a curva de crescimento populacional e a curva de crescimento de edificações. Em 1970, havia 120 edificações, para 574 habitantes; em 2010 havia, 780 edificações para 1.094 habitantes. Ou seja, enquanto a população oficialmente residente aumentou 90,6\%, em quarenta anos, a quantidade de edificações aumentou $650 \%$.

\section{Resultados e Discussões}

$\mathrm{Na}$ ausência de uma política nacional de ordenamento do território, as políticas setoriais, agrícola, segurança, ambiental, energia etc., preenchem este vazio institucional, atendendo parcialmente o disposto no Artigo 21, inciso IX, da Constituição da República (BRASIL, 1988a). Assim, a Política Nacional de Meio Ambiente (PNMA) (BRASIL, 1981), o Plano Nacional de Gerenciamento Costeiro (PNGC) (BRASIL, 1988b) e o Sistema Nacional de Unidades de Conservação (SNUC) (BRASIL, 2000) constituem alguns dos principais instrumentos setoriais de política de ordenamento territorial no país (KOHLHEPP, 2002. MIRAGAYA; SIGNORI, 2011. PERES; CHIQUITO, 2012. FOLETO, 2013. SANCHO, 2017. FRANÇA, 2019).

Apesar do avanço que essa normatização representou para incrementar e direcionar o esforço conservacionista, as Unidades de Conservação no Brasil apresentam uma série de problemas de governança. A dificuldade de articulação entre instituições e a escassez de suporte político, financeiro, estrutural e humano 
acentuam a fragilidade da gestão ambiental e dos processos participativos (FRANÇA, 2019). Ainda que as UCs se ajustem legitimamente aos esforços coordenados de ordenamento territorial para a proteção da biodiversidade e o desenvolvimento sustentável, nem sempre há transparência das reais motivações e interesses envolvidos em sua criação (BARROS, 2010). Para além do interesse público de proteger o commons ecológico, interferem razões econômicas privadas, interessadas em manter reservas de capital natural e formação de bancos genéticos para extração de valor com a aplicação de novas biotecnologias.

Embora muitas mudanças institucionais tenham ocorrido no Brasil desde a criação, em 1930, do primeiro Parque Nacional do país, em Itatiaia, prevalece o fundamento da separação entre sociedade e natureza. Por este princípio, a presença humana não é permitida nos territórios designados para proteção ambiental (SOUZA; MILANEZ, 2015). Há quase um século predomina no Brasil o modelo de conservação que classifica todas os tipos de sociedades desiguais como sendo igualmente depletoras dos ecossistemas naturais (CASTRO-JR; COUTINHO; FREITAS, 2009. SPINOLA, 2013). Noutro extremo ideológico, expressam-se os que classificam os conservacionistas como obstáculo ao desenvolvimento econômico, local ou global (LASCHEFSKI; ZHOURI, 2019).

Na comunidade da Ponta Oeste, em nome da conservação ambiental, a ação dos agentes públicos, violou preceitos da Constituição brasileira (BRASIL, 1988a), da Lei Federal 9.985/2000 (BRASIL, 2000), que regulamentou o Sistema Nacional de Unidades de Conservação, e da Lei Federal 6040/2007 (BRASIL, 2007), de defesa das comunidades tradicionais, indígenas e quilombolas. Ademais, o Decreto Estadual no 4242/2009 (PARANÁ, 2009b), que regulamentou o ordenamento territorial da Ilha do Mel, contraria um entendimento tácito entre a comunidade e 0 Estado, expresso no Plano de Zoneamento de 1981. Harder e Freitas (2015) argumentam que a situação exemplifica o modelo autoritário de controle, no qual as 'razões de Estado' legitimam a exclusão das racionalidades culturalmente diferentes, não hegemônicas, socialmente minoritárias e sem acesso aos mecanismos de capital político.

O Decreto de criação da Estação Ecológica havia limitado a extensão da vila em 31,77 hectares, com a proibição de novas construções e o não reconhecimento de direitos individuais de uso da terra (PARANÁ, 1982). Apesar disso, o próprio Estado instalou aí a primeira escola da ilha, em 1985, e manteve na vila, até 1990, a única zona eleitoral insular. Além da escola, contava com infraestrutura de 
atendimento à saúde e uma igreja construída em alvenaria. Antes da imposição da Estação Ecológica em seus domínios territoriais, a Comunidade da Ponta Oeste constituía-se no maior núcleo habitacional da llha do Mel, abrigando um terço da população, com 211 habitantes, no censo de 1980 (SEMA; IAP, 1996). Em 2017, quando se realizou esta pesquisa de campo, a população no local era de 25 pessoas, com idade média de 60 anos.

As Comunidades locais não foram consultadas sobre a criação das Unidades de Conservação. Após a instalação da Estação Ecológica, os residentes da Ponta Oeste foram coagidos, por ameaça policial de aprisionamento, a abandonar suas casas na vila e não utilizar o local nem para pescar (PARANÁ, 2012). De uma só vez, sacaram-lhes as terras e o mar, dos quais dependiam para obter os meios de subsistência.

Na lógica da Política Nacional de Meio Ambiente e do Sistema Nacional de Unidade de Conservação, enquanto as comunidades nativas não podem permanecer em suas terras, os turistas de qualquer região do planeta são incentivados a desfrutar das terras conservadas libertadas dos nativos que as conservaram até então. Assim, a llha do Mel tornou-se um destino turístico valorizado por políticas e investimentos governamentais em unidades de conservação e novas infraestruturas para recebimento de visitantes (atracadouro de embarcações, energia elétrica, saneamento, comunicação, etc.). Se na década de 1970, a pesca consistia na principal fonte de renda da população, ao final da década de 1990 o turismo havia se convertido na principal fonte de renda da maioria das famílias (GONZAGA; DENKEWICZ; PRADO, 2014).

Numa pesquisa, realizada na primeira década do terceiro milênio, quando se estimava uma população de 910 habitantes, Fuzetti e Corrêa (2009) contabilizaram apenas 98 pescadores na llha. Destes, apenas sete por cento tinha algum filho trabalhando na pesca. A pesca era tradição das famílias, aprendido com os pais e avós, mas modernização da infraestrutura da ilha, que atraiu os empreendedores do continente para investirem em empresas de serviços turísticos na ilha, propiciou o surgimento de um mercado de trabalho atrativo aos jovens e às mulheres. A perda de autonomia é compensada por um trabalho menos árduo e com menor riscos físicos. Gradualmente, o estilo de vida tradicional da ilha foi se transformando e assimilando padrões de consumo urbanos (GONZAGA; DENKEWICZ; PRADO, 2014). Apenas a Ponte Oeste manteve-se como comunidade tradicional, 
oficialmente reconhecida enquanto tal, mas deixada isolada para extinguir-se, sem acesso aos seus direitos e às políticas públicas sociais.

Em 2009, novas restrições vieram regulamentadas na Lei Estadual 16037/2009, estabelecendo o Plano de Uso da Ilha do Mel (PARANÁ, 2009). Esse plano, além de estabelecer o novo ordenamento territorial da ilha e prever a execução de educação ambiental continuada, também replica o dispositivo constitucional do direito cidadão de participação popular na formulação, implementação e avaliação das políticas públicas. Mas, paradoxalmente, sem consultas ou conversas, reduziu o território da Ponta Oeste de apenas 31,8 hectares, para insignificantes 1,6 hectares (PARANÁ, 2009).

Devido ao cerceamento do direito de permanecer na terra de seu pertencimento, os nativos da Ponta Oeste demandaram judicialmente uma alteração da Lei Estadual 16037/2009, que instituiu o Plano de Uso da llha do Mel (PARANÁ, 2009). Baseando-se no Artigo $7^{\circ}$, inciso IV, que designa aquela localidade como Área de Ocupação de População Tradicional Local (AOPT), a comunidade evoca o Decreto Federal 6.040/2007 (BRASIL, 2007), que institui a Política Nacional de Desenvolvimento Sustentável dos Povos e Comunidades Tradicionais. Por ele são reconhecidos os direitos de preservação cultural, práticas comunitárias, identidade étnica, territórios e acesso aos recursos naturais que tradicionalmente utilizam para a reprodução física, cultural e econômica.

As demandas específicas incluíram o reconhecimento do território tradicional da comunidade, com o restabelecimento da fronteira territorial definida pela legislação anterior, de 31,77 hectares; o reconhecimento do espaço oceânico da vila como inseparável do espaço terrestre; o direito de realizar reformas de manutenção em suas casas; e o reconhecimento de direitos individuais para efeitos de uso da terra (ANPPO, 2017). Acrescentando como base a Convenção 169, da Organização Internacional do Trabalho (BRASIL, 2004) e os princípios constitucionais brasileiros, a comunidade solicitou, também, o atendimento ao direito de consulta prévia, livre e informada, sobre a proposta de alteração da Lei 16.037/2009 (MPPR, 2012; 2016; 2017; ANPPO, 2017).

Enquanto preparávamos este artigo para publicação, durante o lockdown da pandemia de Covid-19, os legisladores do Estado do Paraná atenderam as demandas da comunidade da Ponta Oeste. Com a aprovação da Lei Estadual 20244/2020, foram remediados os erros da Lei Estadual 16037/2009. Assim ficou assegurado o território original da comunidade; garantido o direito à renovação da 
infraestrutura e estabelecido direito individual de uso da terra, bem como a participação cidadã nas iniciativas de conservação ambiental (IAP, 2020). A resistência social valeu a pena, a justiça ambiental foi feita, e nem todos tenham sobrevivido para desfrutar.

\section{Considerações Finais}

As decisões sobre o Ordenamento Territorial da Ilha do Mel foram realizadas sem observação dos princípios constitucionais de participação subsidiária em decisões públicas de interesse coletivo. Mesmo em nome da sustentabilidade e do bem-estar da população, as heranças de um passado autoritário não muito distante ainda ecoam nas engenharias institucionais tecnocráticas, em contraposição à possibilidade de arranjos institucional participativo. Constitui-se prática que reforça a injustiça ambiental contra minorias étnicas e sociais, expondo populações tradicionalmente autossustentáveis aos riscos da pobreza, fome e insegurança social.

O caso da resistência da comunidade de pescadores da Ponta Oeste, na llha do Mel, contra as restrições de uso do território por conta da criação de uma Unidade de Conservação, permite uma reflexão sobre as contradições da gestão pública nos processos complexos de buscar o desenvolvimento sustentável. Embora o governante que assinou as leis restritivas fizesse estardalhaço de seu posicionamento democrático e antielitista, sua prática de democracia impôs instrumentos de opressão a minorias sociais sem voz nos fóruns formais das decisões políticas institucionalizadas. Mas, se por um lado, a atuação tecnocrática dos agentes públicos oprimiu e destituiu direitos legítimos amparados em aparatos jurídicos que resultaram questionáveis, por outro lado, a atuação de equilíbrio de forças do Ministério Público, mostrou a vitalidade dos fundamentos da democracia no país.

Uma das principais lições desse movimento de resistência civil é a de que as injustiças podem ser revertidas e a persistência pode trazer os resultados desejados, mesmo que tardiamente. Infelizmente, os custos sociais dos erros da administração pública são altos, consomem recursos valiosos e as responsabilidades são difusas em meio a um arcabouço de decisões burocráticas anônimas, eventualmente legitimadas pelo aval de algum governante legitimamente investido num cargo público. Mas embora aos governantes e burocratas não Ihes afetem pessoalmente 
decisões tomadas com base em princípios gerais, como a conservação ambiental e o desenvolvimento sustentável, tudo o que se refere às opções de políticas sobre ordenamento do território impactam negativamente na vida de pessoas e coletividades sem capital político.

Submetida ao isolamento e desamparada pela gestão pública, a comunidade da Ponta Oeste, ao demandar justiça socioambiental, ainda que não lhe atribuíssem essa designação, exemplificou de modo vivencial a noção de que o território não é um pedaço de terra, mas é o conjunto composto por uma identidade simbólica associada à percepção de pertencimento ao lugar. $O$ território existe onde se manifesta a identificação com o espaço das atividades de trocas materiais e espirituais na vida ativa cotidiana, conforme afirmava Santos (2000). Porque as condições das relações dos indivíduos com o seu meio ambiente constituem a base de referência para a realidade socialmente construída, na qual se institucionalizam as identidades coletivas de um local (GONZAGA, 2018).

A resistência da comunidade nativa de pescadores da Ponta Oeste parece emergir desse pertencimento radical, no sentido enraizamento ao lugar em que elaboraram sua história e imaginaram seu futuro. Ali mesmo, onde somente eles compreendem o significado de pertencer aquele pedaço da Terra. Assim, enquanto passam os transatlânticos desfilando, indiferentes, milhares de contêineres com riquezas oriundas de vários solos do mundo, a riqueza mais almejada por essa população nativa consistia em obter o direito de permanência em 31,77 hectares de terra, em cujas areias rebatem as marolas do canal do Porto de Paranaguá.

Leis e normas tem o poder de fazer com que as comunidades nativas sejam reclassificadas de agentes da sustentabilidade ancestral para invasores do território onde tradicionalmente residiram seus ancestrais e de onde retiram sua subsistência. Mas as leis não podem impedir de se mantenham vivos os elementos das tradições culturais, os vínculos à terra e ao mar, os quais evocam e fortalecem a memória e o sentimento de coletividade. Não como eco repetitivo do passado, mas como cidadania de um presente pleno de incertezas, dúvidas e desafios a serem descerrados. Rumo a um futuro que ainda não está pronto.

As comunidades locais não querem ser excluídas da preservação de seu ambiente. Os conflitos socioambientais requerem diálogo político. Supõe-se que o estabelecimento de áreas de conservação resguardará o meio ambiente para as gerações futuras. Mas quais gerações, se das populações atuais forem subtraídos o direito sobre os recursos naturais que lhes sustenta o presente? 


\section{REFERÊNCIAS}

ACSELRAD, H. As práticas espaciais e o campo dos conflitos ambientais. In: ACSELRAD, H. (org). Conflitos Ambientais no Brasil. Rio de Janeiro: Relume Dumará; Fundação Heinrich Böll, 2004 (p.13-36).

ACSELRAD, H. Ambientalização das lutas sociais: o caso do movimento por justiça ambiental. Estudos Avançados, v.24, n.68, p.103-119, 2010.

ACSELRAD, H.; MELLO, C. C.; BEZERRA, G. O que é justiça ambiental. Rio de Janeiro: Garamond, 2009.

ADAMS, W. M.; HUTTON, J. People, parks and poverty: Political ecology and biodiversity conservation. Conservation \& Society, v.5, n.2, p.147-183, 2007.

ALTVATER, E. Ilhas de sintropia e exportação de entropia: custos globais do fordismo fossilístico. Cadernos NAEA, n.11, p.3-54, 1993.

ANGUELOVSKI, I. Environmental Justice. In: D’ALISA, G.; DEMARIA, F.; KALLIS, G. Degrowth: a vocabulary for a new era. New York; London: Routledge, 2015.

ANPPO (Associação dos Nativos e Pescadores da Ponta Oeste). Protocolo de Consulta Comunidade Tradicional da Ponta Oeste, Ilha do Mel, Baia de Paranaguá, Brasil. Paranaguá, 2017.

BARBESGAARD, M. Blue growth: savior or ocean grabbing? The Journal of Peasant Studies, v.45, n.1, p.130-149, 2018.

BARROS, L. F. F. O uso e ocupação sobre áreas de preservação permanente na APA Jenipabu (RN, Brasil) e seu caráter conflitivo: onde fica o ordenamento territorial?

Sociedade e Território, v.22, n.2, p. 37-54, 2010.

BERKES, F. et al. Globalization, roving bandits, and marine resources. Science, v.311, p.1557-1558, 2006.

BIERMANN, F. Earth system governance: World politics in the Anthropocene. Cambridge, MA: MIT Press, 2014.

BRASIL. Lei $n^{\circ}$ 6.938, de 31 de agosto de 1981. Dispõe sobre a Política Nacional do Meio Ambiente, seus fins e mecanismos de formulação e aplicação, e dá outras providências.

Diário Oficial da União. Brasília, 02/09/1981.

BRASIL. Constituição da República Federativa do Brasil: promulgada em 5 de outubro de 1988. Brasília: Senado, 1988a.

BRASIL. Lei no 7.661, de 16 de maio de 1988. Institui o Plano Nacional de Gerenciamento Costeiro e dá outras providências. Diário Oficial da União. Brasília, 18/05/1988b.

BRASIL, Lei no 9985, de 18 de julho de 2000. Regulamenta o art. 225, § 10, incisos I, II, III e VII da Constituição Federal, institui o Sistema Nacional de Unidades de Conservação da Natureza e dá outras providências. Diário Oficial da União. Brasília, 19/07/2000.

BRASIL. Decreto № 5.051, de 19 de abril de 2004. Promulga a Convenção no 169 da Organização Internacional do Trabalho (OIT) sobre Povos Indígenas e Tribais. Diário Oficial da União, Brasília, 20/04/2004. 
BRASIL. Decreto Federal no 6.040, de 7 de fevereiro de 2007. Institui a Política Nacional de Desenvolvimento Sustentável dos Povos e Comunidades Tradicionais. Diário Oficial da União. Brasília, 08/02/2007.

BÜSCHER, B.; FLETCHER, R. Towards convivial conservation. Conservation \& Society, v.17, n.3, p.283-296, 2019.

BÜSCHER, B.; FLETCHER, R. The conservation revolution: Radical ideas for saving nature beyond the Anthropocene. London: Verso, 2020.

CASTRO JÚNIOR, E.; COUTINHO, B. H.; FREITAS, L. E. Gestão da biodiversidade e áreas protegidas. In: GUERRA, A. J. T.; COELHO, M. C. N. Unidades de conservação: abordagens e características geográficas. Rio de Janeiro: Bertrand Brasil, 2009 (p.25-66).

CHIARELLA, R. Redes y território: la iniciativa IIRSA en foco. Espacio y Desarrollo, n.23, p.5-29, 2011.

COSTA, F. A. Contributions of fallow lands in the Brazilian Amazon to $\mathrm{CO} 2$ balance, deforestation and the agrarian economy: Inequalities among competing land use trajectories. Elementa Science of the Anthropocene, n.4, p.000133, 2016.

CRUTZEN, P. J. Geology of Mankind. In: CRUTZEN P., BRAUCH H. (eds). Paul J. Crutzen: A pioneer on atmospheric chemistry and climate change in the Anthropocene. Cham, Switzerland: Springer, 2016. (SpringerBriefs on Pioneers in Science and Practice, v.50, p.211-215).

CRUTZEN, P. J. The "anthropocene." Journal de Physique IV (Proceedings), v.12, n.10, p.1-5, 2002. DOI:10.1051/jp4:20020447.

DENKEWICZ, P. Turismo, proteção ambiental e inclusão social na Ilha do Mel, Litoral do Paraná. 2020. 242f. Tese (Doutorado em Meio Ambiente e Desenvolvimento) Universidade Federal do Paraná, Curitiba, 2020.

DINIZ, M. T. M. et al. Paisagens integradas dos municípios costeiros da Foz do Rio São Francisco: Brejo Grande/SE e Piaçabuçu, AL. Revista do Departamento de Geografia, v.37, p.108-122, 2019.

DOUVERE, F. The importance of marine spatial planning in advancing ecosystem-based sea use management. Marine Policy, v.32, n.5, p.762-771, 2008.

FOLETO, E. M. As políticas públicas de conservação no ordenamento territorial.

Geoambiente, n.21, 2013.

FOLEY, J. A., et al. Global consequences of land use. Science, v.309, n.5734, p.570-574, 2005.

FRANÇA, E. B. Ordenamento territorial e gestão em unidades de conservação de ambientes costeiros. Revista GeoNordeste, v.30, n.1, p.200-219, 2019.

FUZETTI, L.; CORRÊA, M. F. M. Perfil e renda dos pescadores artesanais e das vilas da Ilha do Mel - Paraná, Brasil. Boletim do Instituto de Pesca, v.35, n.4, p.609-621, 2009.

GONZAGA, C. A. M. Pobreza e meio ambiente: conexões e potencialidades. In: SERPE, B. M.; SILVA, L. A. M. (org.). Desenvolvimento, gênero e pobreza. Ponta Grossa: UEPG, 2018 (p.37-49). 
GONZAGA, C. A. M.; DENKEWICZ, P.; PRADO, K. C. P. Unidades de Conservação, ecoturismo e conflitos socioambientais na llha do Mel (PR), Brasil. Revista ADMpg Gestão Estratégica, v.7, n.1, p.61-67, 2014.

HARDER, E.; FREITAS, A. E. C. Envelhecer na invisibilidade: tempo e narrativa na Ponta Oeste da llha do Mel, Paraná, Brasil. Revista lluminuras, v.16, n.40, 2015.

HOSOKAWA, R. T.; HOSOKAWA, E. G. A lei dos efeitos acelerados da entropia e o limite no uso de recursos energéticos da biosfera. Floresta, v. 31, n. 1/2, 2001.

HUTTON, J.; ADAMS, W. M.; MUROMBEDZI, J. C. Back to the barriers? Changing narratives in biodiversity conservation. Forum for development studies, v.32, n.2, p.341370, 2005.

IAP (Instituto Ambiental do Paraná). Plano de Manejo do Parque Estadual da Ilha do Mel. Curitiba: IAP, 2012.

IAP (Instituto Ambiental do Paraná). Projeto de lei prevê medidas ambientais e territoriais na llha do Mel. Disponível em:< http://www.iap.pr.gov.br/2020/05/1682/Projetode-lei-preve-medidas-ambientais-e-territoriais-na-Ilha-do-Mel.html>. Acesso em: 26/08/2020.

IBGE (Instituto Brasileiro de Geografia e Estatística). Censo demográfico 2010 Brasília: IBGE, 2010.

KOHLHEPP, G. Conflitos de interesse no ordenamento territorial da Amazônia brasileira. Estudos avançados, v.16, n.45, p.37-61, 2002.

LADEIRA, M. I. Os índios Guarani e as Ilhas do Paraná. São Paulo: Centro de Trabalho Indigenista, 1990.

LASCHEFSKI, K.; ZHOURI, A. Povos indígenas, comunidades tradicionais e meio ambiente: a 'questão territorial' e o novo desenvolvimentismo no Brasil. Terra Livre, v.1, n.52, p.241285, 2019.

LETCHER, T. M.; VALLERO, D. A. (ed.). Waste: A handbook for management. 2 ed. London: Elsevier, 2019. ISBN: 978-0-12-815060-3.

LIMA, L. C.; BRASIL, L. K. B.; LOCATEL, C. D. A dimensão geográfica de políticas públicas: o Programa de Aquisição de Alimentos (PAA) e a Política Nacional de Economia Solidária (ECOSOL) no Rio Grande do Norte. Confins, n.34, 2018.

LIRA, T. M.; WITKOSKI, A. C. Floresta Estadual de Maués como artefato humano. Seminário Internacional de Ciências do Ambiente e Sustentabilidade na Amazônia, 4, Manaus, 2016. Anais... São Paulo: ANPPAS, 2016.

MAESTRO, M. et al. Marine protected areas in the 21st century: Current situation and trends. Ocean \& Coastal Management, v.171, p.28-36, 2019.

MALM, A.; HORNBORG, A. The geology of mankind? A critique of the Anthropocene narrative. The Anthropocene Review, v.1, n.1, p.62-69, 2014.

MARQUES, C. Por uma compreensão da crise ambiental e do paradigma do risco. Caderno de Relações Internacionais, v.4, n.7, p.75- 95, 2013.

MARTINEZ-ALIER, J. Ecological distribution conflicts and indicators of sustainability.

International Journal of Political Economy, v.34, n.1, p.13-30, 2004. 
MARTINEZ-ALIER, J; WALTER, M. Social metabolism and conflicts over extractivism. In: CASTRO, F.; HOGENBOOM, B.; BAUD, M. (ed.). Environmental Governance in Latin America. Hampshire, UK: Palgrave Macmillan, 2016.

MEA (Millennium Ecosystem Assessment). Ecosystems and human well-being: biodiversity synthesis. Washington, DC: Island Press, 2005.

MENON, G.; GONZAGA, C. A. M. O planejamento público contempla as demandas da sociedade?: Uma análise do PPA 2016-2019 do Estado do Paraná. Anais do Congresso Internacional de Administração - ADM-2017. Ponta Grossa, PR: UEPG, 2017.

MIRAGAYA, J.; SIGNORI, L. A importância da Política Nacional de Ordenamento Territorial (PNOT) para o Desenvolvimento Sustentável brasileiro. In: FARIA, R.; SCHVARSBERG, B. (org.). Políticas urbanas e regionais no Brasil. Brasília: UnB, 2011 (p.137-167).

MONTEIRO, F. T.; PEREIRA, D. B.; GAUDIO, R. S. Os(as) apanhadores(as) de flores e o Parque Nacional das Sempre-Vivas: entre ideologias e territorialidades. Sociedade \& Natureza, v.24, n.3, 2012.

MPPR (Ministério Público do Paraná) - Direitos Humanos. Recomenda que IAP reconheça legitimidade de ocupação no Litoral. Releases 14/11/2012

MPPR (Ministério Público do Paraná) - Direitos Humanos. CAOPJDH recomenda à SEMA medidas e procedimentos adequados para a realização do Direito à consulta prévia, livre e informada junto à Comunidade de Pescadores Artesanais da Ponta Oeste. Central de Comunicação Social do MPPR. Curitiba, 29/09/2016.

MPPR (Ministério Público do Paraná) - Direitos Humanos. Comunidade de Pescadores Artesanais da Ilha do Mel elabora seu Protocolo de Consulta Prévia, Livre e Informada. Central de Comunicação Social do MPPR. Curitiba, 25/08/2017.

NEILSON, A. L.; CASTRO, I. Reflexive research and education for Sustainable Development with coastal fishing communities in the Azores Islands: A theatre for questions. In: CASTRO P. et al. (eds). Biodiversity and Education for Sustainable Development. (World Sustainability Series). Switzerland: Springer, 2016 (p.203-217).

NEILSON, A. L.; SÃO MARCOS, R. Civil participation between private and public spheres: The island sphere and fishing communities in the Azores archipelago. Island Studies Journal, v.11, n.2, p.585-600, 2016.

OST, F. La nature hors la loi: L'écologie à l'épreuve du droit. Paris: La Découverte, 1995.

PAGANI, R. N.; KOVALESKI, J. L.; RESENDE, L. M. Methodi Ordinatio: a proposed methodology to select and rank relevant scientific papers encompassing the impact factor, number of citation, and year of publication. Scientometrics, n.105, p109-135, 2015.

PARANÁ. Decreto Estadual no 5.454, de 21 de setembro de 1982. Cria a Estação Ecológica da Ilha do Mel. Diário Oficial do Estado do Paraná. Curitiba, 22/09/1982.

PARANÁ. Decreto Estadual no. 5.506, de 21 de março de 2002. Cria o Parque Estadual da Ilha do Mel, localizado no município de Paranaguá. Diário Oficial do Estado do Paraná, n.6195. Curitiba, 22/03/2002.

PARANÁ. Lei Estadual no. 16.037, de 08 de Janeiro de 2009. Dispõe que a llha do Mel, situada na baía de Paranaguá, Município de Paranaguá, constitui região de especial interesse ambiental e turístico do Estado do Paraná, conforme especifica. Diário Oficial do Estado do Paraná, n.7885. Curitiba, 08/01/2009. 
PARANÁ. Decreto Estadual no 4.242, de 09 de fevereiro de 2009. Regulamenta a Lei nº 16.037, de 08 de janeiro de 2009, a qual dispõe que a llha do Mel, situada na baía de Paranaguá, Município de Paranaguá, constitui região de especial interesse ambiental e turístico do Estado do Paraná. Diário Oficial do Estado do Paraná, no. 7.907. Curitiba, 09/02/2009b.

PARANÁ - Coordenadoria do Patrimônio Cultural da Secretaria de Estado da Cultura. Parecer Técnico "Ponta Oeste - Illha do Mel", Paranaguá (PR), de 03 de setembro de 2012. Referente à solicitação realizada pela Associação de Pescadores da Comunidade de Ponta Oeste - Ilha do Mel à CPC-SEEC, em ofício datado de 02 de abril de 2012, para elaboração de estudos sobre a história da comunidade tendo como suporte o protocolo no 11.131.381-4, de 03 de novembro de 2012. Curitiba, 2012.

PERES, R. B.; CHIQUITO, E. A. Ordenamento territorial, meio ambiente e desenvolvimento regional: novas questões, possíveis articulações. Revista Brasileira de Estudos Urbanos e Regionais, v.14, n.2, p.71, 2012.

PIERRI, N. El proceso histórico e teórico que conduce a la propuesta del desarrollo sustentable. In: PIERRI, N.; FOLADORI, G; (Org.). ?Sustentabilidad? Desacuerdos sobre el Desarrollo Sustentable. Montevidéu: Trabajo y Capital, 2001 (p.27-80).

POTDAR, A. et al. Innovation in Solid Waste Management through Clean Development Mechanism in Developing Countries. Procedia Environmental Sciences, v.35, p.193-200, 2016.

SANCHO, A. Ordenamento territorial e áreas protegidas: um olhar sobre o processo de criação do Parque Nacional da Serra do Cipó, MG. GOT - Revista de Geografia e Ordenamento do Território, n.12, p.309-333, 2017.

SANTOS, M. Por outra globalização: do pensamento único à consciência universal. Rio de Janeiro: Record, 2000.

SANTOS, C. Z.; SCHIAVETTI, A. Spatial analysis of Protected Areas of the coastal/marine environment of Brazil. Journal for Nature Conservation, v.22, n. 5, p.453-461, 2014.

SEMA; IAP (Secretaria de Estado do Meio Ambiente; Instituto Ambiental do Paraná). Plano de manejo da Estação Ecológica da Ilha do Mel, PR. Curitiba: IAP, 1996.

SONG, X.-P, et al. Global land change from 1982 to 2016. Nature, v.560, p.639-643, 2018.

SOUZA, L. R. C.; MILANEZ, B. Conflitos socioambientais e áreas protegidas no Brasil: algumas reflexões. Revista de Geografia, v.5, n.1, p.43-57, 2015.

SPINOLA, C. A. O ecoturismo, o desenvolvimento local e a conservação da natureza em espaços naturais protegidos: objetivos conflitantes? RDE - Revista de Desenvolvimento Econômico, v.8, n.13, p.50-59, 2006.

SPINOLA, C. A. Parques nacionais, conservação da natureza e inserção social: uma realidade possível em quatro exemplos de cogestão Turismo - Visão e Ação, v.15, n.1, p.71-83, 2013.

STEFFEN, W. et al. The Anthropocene: conceptual and historical perspectives.

Philosophical Transactions of the Royal Society A: Mathematical, Physical and Engineering Sciences, v.369, n.1938, p.842-867, 2011.

WESTPHAL, E. Para além do paraíso: uma reinterpretação sociológica do discurso ambiental sobre as identidades de grupos tradicionais e de suas práxis religiosas populares 
na Ilha do Mel. 2014. 305F. Tese (Doutorado em Sociologia) - Universidade Federal do Paraná, Curitiba, 2014.

ZHOURI, A.; LASCHEFSKI, K. (org.). Desenvolvimento e conflitos ambientais. Belo Horizonte: UFMG, 2010.

\section{NOTAS DE AUTOR}

\section{CONTRIBUIÇÃO DE AUTORIA}

Carlos Alberto Marçal Gonzaga - Concepção e elaboração do manuscrito. Análise de dados, Participação ativa da discussão dos resultados; Revisão e aprovação da versão final do trabalho.

Patrícia Denkewicz - Concepção. Coleta de dados, Análise de dados, Elaboração do manuscrito, revisão e aprovação da versão final do trabalho

Rui Pedro Julião - Revisão e aprovação da versão final do trabalho.

\section{FINANCIAMENTO}

Não se aplica.

\section{CONSENTIMENTO DE USO DE IMAGEM}

Não se aplica.

\section{APROVAÇÃO DE COMITÊ DE ÉTICA EM PESQUISA}

Não se aplica.

\section{CONFLITO DE INTERESSES}

Não se aplica.

\section{LICENÇA DE USO}

Este artigo está licenciado sob a Licença Creative Commons CC-BY. Com essa licença você pode compartilhar, adaptar, criar para qualquer fim, desde que atribua a autoria da obra.

\section{HISTÓRICO}

Recebido em: 27-08-2020

Aprovado em: 16-04-2021 